\title{
Prototipe Pendeteksi Titik Gangguan pada Jaringan 20 kV dengan Metode Arus Gangguan
}

\author{
Alwi Daffa` Rosydi', Eka Prasetyono², Novie Ayub Windarko ${ }^{3}$ \\ Program Studi Teknik Elektro Industri, \\ Departemen Teknik Elektro, \\ Politeknik Elektronika Negeri Surabaya, Surabaya \\ 1alwidaffa@gmail.com, 2eka@pens.ac.id, 3ayub@pens.ac.id
}

\begin{abstract}
Ringkasan
PT. PLN (Persero) merupakan Badan Usaha Milik Negara (BUMN) yang bergerak dibidang pembangkitan dan pendistribusian tenaga listrik bagi seluruh masyarakat Indonesia. Pada proses distribusi sering terjadi gangguan hubungan singkat yang diakibatkan banyak faktor diantaranya faktor eksternal atau faktor alam yang berupa ranting pohon maupun hewan. Dari data pada sebuah wilayah Unit Pelaksana Pelayanan Pelanggan (UP3) dalam sebulan gangguan bisa terjadi hingga 70 kali dan memerlukan waktu penanganan 15 menit hingga 1 jam. Karena penanganan masih dengan cara mengukur impedansi sepanjang jaringan yang dimana sebuah penyulang bisa memiliki panjang hingga $50 \mathrm{kms}$. Oleh karena itu dibutuhkan alat yang dapat mendekteksi titik gangguan serta jenis gangguan yang terjadi pada jaringan. Untuk merealisasikan alat tersebut diperlukan prototype jaringan tegangan menengah yang dapat mensimulasikan gangguan hubung singkat satu fasa ke tanah, dan antar fasa. Prototype ini menggunakan mikrokontroler yang akan difungsikan sebagai relay over current dan saat ada gangguan hubung singkat mikrokontroler juga akan langsung melakukan perhitungan lokasi gangguan dari relay yang trip berdasarkan besar arus gangguan yang dideteksi oleh relay. Pada alat ini terdapat LCD yang digunakan untuk menampilkan besar arus gangguan serta jenis gangguan yang terjadi dan diharapkan dapat mempermudah serta mempercepat petugas untuk melakukan penormalan kembali pada jaringan yang mengalami gangguan.
\end{abstract}

Kata kunci: Deteksi lokasi gangguan, Gangguan fasa ke tanah, Gangguan fasa ke fasa

\section{Pendahuluan}

PT PLN (Persero) adalah perusahaan jasa yang bergerak dibidang penyediaan tenaga listrik untuk masyarakat Indonesia dan merupakan salah satu Badan Usaha Milik Negara (BUMN) yang dipercaya menyelenggarakan pelayanan umum. PT PLN (Persero) dituntut untuk memberikan pelayanan yang memuaskan bagi seluruh pelanggannya. Berdasarkan data, pada proses penyaluran tenaga listrik khususnya pada saluran udara tegangan menengah (SUTM) sering terjadi gangguan hubung singkat. Dan hubung singkat yang paling sering terjadi ada hubung singkat fasa tanah yang diakibatkan oleh hewan dan ranting pohon yang menyentuh jaringan. Dalam sebulan gangguan hubung singkat yang terjadi pada sebuah wilayah Unit Pelaksana Pelayanan Pelanggan (UP3) bisa mencapai lebih dari 70 kali gangguan[1].

Gangguan ini sangat mengganggu proses distribusi karena sering kali memiliki waktu padam yang relatif lama yaitu 15 menit hingga 1 jam. Hal ini terjadi karena cara 
penanganan saat ini masih dengan cara melakukan pengukuran sepanjang penyulang dan cara ini kurang efektif karena di sebuah penyulang bisa memiliki panjang hingga 50 Kms. Serta dari data seharusnya PLN bisa menjual kWh hingga $130.000 \mathrm{kWh}$ namun karena gangguan $\mathrm{kWh}$ sebesar itu tidak terjual dan PLN mengalami kerugian. Diharapkan alat ini akan mempersempit pencarian lokasi gangguan dan membuat petugas cepat mengatasi gangguan yang terjadi.

\section{Dasar Teori}

\subsection{Gangguan Hubung Singkat}

Dalam operasi sistem tenaga listrik sering terjadi gangguan - gangguan yang dapat mengakibatkan terganggunya penyaluran tenaga listrik ke konsumen. Gangguan adalah penghalang dari suatu sistem yang sedang beroperasi atau suatu keadaan dari sistem penyaluran tenaga listrik yang menyimpang dari kondisi normal. Sesuai dengan SPLN No 2:1978 Pasal 9 bahwa dalam sistem distribusi listrik tiga fasa tiga kawat menggunakan pentanahan dengan tahanan sebagai suatu sistem distribusi yang berlaku untuk wilayah kerja PLN di seluruh Indonesia [2]. Dalam Pasal 10 dijelaskan bahwa untuk sistem Jawa Timur yang menggunakan pentanahan dengan tahanan tinggi maka nilai tahanan yang digunakan adalah $500 \mathrm{Ohm}$ dengan arus gangguan hubung singkat satu fasa ke tanah maksimal 25 A jika mengunakan saluran udara [3]. Pada sistem ini pula arus hubung singkat 2 fasa biasanya lebih kecil dari pada arus hubung singkat 3 fasa. Sedang arus gangguan 1 fasa ketanah hampir selalu lebih kecil daripada arus hubung singkat 3 fasa karena [4]:

1. Umumnya impedansi urutan nolnya lebih besar dari pada impedansi urutan positif/ negatif.

2. Gangguan tanah melalui tahanan gangguan.

3. Untuk pentanahan yang menggunakan tahanan, tahanan netralnya akan membatasi arus gangguan 1 fasa ke tanah.

Kondisi sebaliknya terjadi (gangguan 1 fasa ke tanah lebih besar dari pada arus hubung singkat 3 fasa) apabila lokasi gangguan berada di pusat pembangkit atau dekat pusat pembangkit pada sistem dengan pentanahan langsung (solid grounded).

\subsection{Penyebab Gangguan Hubung Singkat}

Gangguan biasanya diakibatkan oleh kegagalan isolasi di antara penghantar fasa atau antara penghantar fasa dangan tanah[5][6]. Secara nyata kegagalan isolasi dapat menghasilkan efek pada sistem yakni menghasilkan arus yang cukup besar. Ada beberapa faktor yang menyebabkan terjadinya gangguan, antara lain sebagai berikut :

\section{Faktor Manusia}

Faktor ini terutama menyangkut kesalahan atau kelalaian dalam memberikan perlakuan pada sistem. Misalnya salah menyambungkan rangkaian, salah dalam mengkalibrasi suatu piranti pengaman, dan sebagainya.

\section{Faktor Internal}

Faktor ini menyangkut gangguan - gangguan yang berasal dari sistem itu sendiri. Misalnya usia pakai, keausan, dan sebagainya. Hal ini bisa mengurangi sensitivitas relai pengaman, juga mengurangi daya isolasi peralatan listrik lainnya. 


\section{Faktor Eksternal}

Faktor ini meliputi gangguan - gangguan yang berasal dari lingkungan di sekitar sistem misalnya cuaca, gempa bumi, banjir, dan sambaran petir. Disamping itu ada kemungkinan gangguan dari binatang.

Gangguan-gangguan tersebut menyebabkan terjadinya:

1. Interupsi kontinuitas pelayanan daya kepada para konsumen apabila gangguan itu sampai menyebabkan terputusnya suatu rangkaian (circuit) atau menyebabkan keluarnya satu unit pembangkit.

2. Penurunan tegangan yang cukup besar menyebabkan rendahnya kualitas tenaga listrik dan merintangi kerja normal pada peralatan konsumen.

\section{3. $\quad$ Menghitung Impedansi Ekivalen Penyulang}

Perhitungan yang akan dilakukan adalah perhitungan besarnya nilai impedansi ekivalen dari nilai positif (Z1eq), negatif (Z2eq) dan nol (Z0eq) dari titik gangguan sampai ke sumber[7][8].Karena dari sumber ke titik gangguan impedansi yang terbentuk adalah seri, maka perhitungan Z1eq dan Z2eq dapat dilakukan dengan cara langsung menjumlahkan impedansi-impedansi tersebut, sedangkan untuk perhitungan Z0eq dimulai dari titik gangguan sampai ke trafo tenaga yang netralnya ditanahkan.

Untuk perhitugan Z1eq dan Z2eq dilakukan dengan persamaan sebagai berikut :

$$
Z 1 e q=Z 2 e q=Z s 1+Z t 1+Z 1 \text { penyulang }=j 0,8+j 4,0+Z 1 \text { penyulang }
$$

Untuk menghitung Impedansi Z0eq, maka diumpamakan trafo tenaga yang terpasang mempunyai hubungan wye-delta, dimana mempunyai nilai sebesar 12 Ohm, dan nilai tahanan pentahanan $120 \mathrm{Ohm}$.

Untuk perhitungan nilai Z0eq dilakukan dengan persamaan berikut :

$$
Z 0 e q=Z t 0+3 R n+Z 0 \text { penyulang }=j 12+120+Z 0 \text { penyulang }
$$

\subsection{Penulisan Persamaan Matematis}

Persamaan dasar yang digunakan pada perhitungan arus gangguan hubung singkat 2 fasa ini adalah [7][8]:

$$
I=V p h-p h Z
$$

di mana :

$I \quad=$ Arus gangguan hubung singkat

Vph-ph = Tegangan fasa-fasa sistem $20 \mathrm{kV}$

Z $\quad$ = Impedansi

Sehingga dari persamaan diatas dapat diketahui bahwa arus hubung singkat dapat dihitung dengan persamaan:

$$
I=V p h-p h 2 \times Z 1 e q
$$

\subsection{Menghitung Arus Gangguan Fasa ke Fasa}

Persamaan dasar yang digunakan pada perhitungan arus gangguan hubung singkat fasa ke tanah ini adalah persamaan berikut [7][8].

$$
I=V p h-n Z
$$

di mana : 
$I=$ Arus gangguan hubung singkat

$V p h-n=$ Tegangan fasa-netral sistem $20 \mathrm{kV}$

$\mathrm{Z} \quad=$ Impedansi

Sehingga dari persamaan diatas dapat diketahui bahwa arus hubung singkat dapat dihitung dengan persamaan dibawah:

$$
I=V p h-n 2 \times Z 1 e q+Z 0 e q
$$

\section{Perancangan Sistem}

Perencanaan dan pembuatan perangkat berdasarkan blok diagram sistem ditunjukkan pada Gambar 1 berikut :

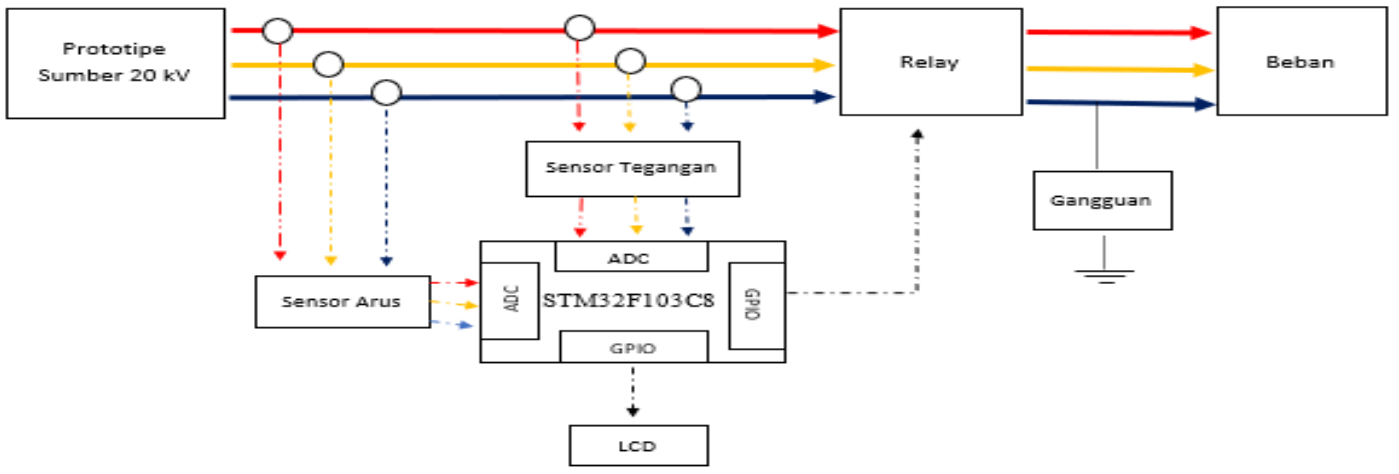

Gambar 1. Blok diagram sistem

Tulisan ini secara umum berupa prototipe yang berfungsi untuk mensimulasikan gangguan short circuit dan memprediksi lokasi gangguan berdasarkan arus gangguan. Mekanisme alat ini yaitu dengan pemodelan jaringan $20 \mathrm{kV}$ menjadi $20 \mathrm{~V}$. Setelah itu dilakukan gangguan short circuit pada jarak tertentu. Setelah besar arus gangguan didapat, kemudian mencari menentukan jenis gangguan dan lokasi gangguan dari besar arus serta tegangan yang didapat dan ditampilkan pada LCD. Untuk mendapatkan hasil seperti yang di harapkan diperlukan beberapa perancangan seperti perancangan modul gangguan, perancangan modul NGR, dan perancangan sensor tegangan.

\subsection{Perancangan Modul Jaringan}

Besar impedansi konduktor AAAC dengan luas penampang 150mm2 sebesar 0,2162 +j0,3305 [10].Menentukan nilai tahanan pengganti[8][9].

$$
Z=R+j X=\sqrt{0,2162^{2}+0,3305^{2}}=0,39 \mathrm{ohm} / \mathrm{km}
$$

\subsection{Perancangan Modul NGR}

Batas arus gangguan fasa tanah maksimal pada jaringan 20kV dengan NGR 500 Ohm adalah sebesar 25 A [8][9][11]. Menentukan nilai tahanan NGR

$$
\mathrm{Ngr}=\frac{V_{L-N}}{I_{\text {SC }}}=\frac{11.5}{25}=0,46 \mathrm{Ohm}
$$




\subsection{Perancangan Sensor Tegangan}

Perhitungan tegangan output penyearah [11]

$$
V_{\text {out }}=\frac{V_{\text {mI }}}{\pi}=\frac{11.5 . \sqrt{2}}{3.14}=\frac{16.26}{3.14}=5.18 \mathrm{~V}
$$

Perhitungan tegangan output degan filter C

$$
V_{\text {out }}=V_{m}-\frac{V_{p n}}{4 f R C}=11.5 \sqrt{2}-\frac{11.5 \sqrt{2}}{4 \times 50 \times 80 \times 10^{3} \times 10 \times 10^{-6}}=16.15 \mathrm{~V}
$$

Perhitungan besar resistor pembagi tegangan

$$
R 2=\frac{\left(R 1 x V_{i n}\right)-\left(R 1 x V_{(G u E}\right)}{V_{\text {DwE }}}=\frac{(10 \mathrm{k} x 16.15)-(10 \mathrm{k} x 1.8)}{1.8}=79722 \Omega \approx 80 \mathrm{k} \Omega
$$

\section{Pengujian Sistem}

\subsection{Modul Gangguan}

Modul Gangguan ini terdiri dari transformator 3 fasa, resistor pengganti konduktor AAAC, dan juga 3 buah lampu yang digunakan sebagai beban. Pengujian dilakukan dengan cara memberikan tegangan sesuai rating yaitu tegangan fasa-fasa sebesar $20 \mathrm{~V}$. Dan data hasil pengujian yang didapat seperti pada Tabel 1.

Tabel 1. Hasil pengujian modul gangguan

\begin{tabular}{|c|c|c|c|c|c|}
\hline No & Fasa & Arus (A) & VP-N $(\mathrm{V})$ & VP-P $(\mathrm{V})$ & VBeban $(\mathrm{V})$ \\
\hline 1 & $\mathrm{R}$ & 0,76 & 11,69 & - & 10,14 \\
\hline 2 & $\mathrm{~S}$ & 0,75 & 11,45 & - & 9,92 \\
\hline 3 & $\mathrm{~T}$ & 0,76 & 11,56 & - & 10 \\
\hline 4 & $\mathrm{R}-\mathrm{S}$ & - & - & 20,10 & 17,10 \\
\hline 5 & $\mathrm{R}-\mathrm{T}$ & - & - & 20,22 & 17,19 \\
\hline 6 & $\mathrm{~S}-\mathrm{T}$ & - & - & 19,81 & 16,96 \\
\hline
\end{tabular}

\section{2. $\quad$ Arus Hubung Singkat}

Pada pengujian ini dilakukan Short Circuit pada modul gangguan yang berfungsi untuk mengetahui besar arus gangguan Short Circuit yang terjadi pada tiap titik pada modul gangguan. Dan dengan hasil pengujian Short Circuit fasa tanah terbesar terjadi pada jarak 1,5 km dengan arus 6,03 A dan arus terkecil pada $6 \mathrm{~km}$ sebesar 3,34 A seperti pada Tabel 2.

Tabel 2. Hasil pengujian arus hubung singkat fasa tanah

\begin{tabular}{|c|c|c|c|c|c|}
\hline \multirow{2}{*}{ No } & \multirow{2}{*}{ Jarak } & \multicolumn{3}{|c|}{ FASA } & \multirow{2}{*}{$\begin{array}{c}\text { Rata- } \\
\text { Rata (A) }\end{array}$} \\
\cline { 3 - 5 } & & $\mathrm{R}(\mathrm{A})$ & $\mathrm{S}(\mathrm{A})$ & $\mathrm{T}(\mathrm{A})$ & 6.03 \\
\hline 1 & $1,5 \mathrm{KM}$ & 6.04 & 5.87 & 6.17 & 5.49 \\
\hline 2 & $2 \mathrm{KM}$ & 5.5 & 5.47 & 5.5 & 4.77 \\
\hline 3 & $3 \mathrm{KM}$ & 4.76 & 4.7 & 4.85 & 4.37 \\
\hline 4 & $3,5 \mathrm{KM}$ & 4.33 & 4.3 & 4.49 & 3.90 \\
\hline 5 & $4,5 \mathrm{KM}$ & 3.88 & 3.86 & 3.97 & 3.69 \\
\hline 6 & $5 \mathrm{KM}$ & 3.66 & 3.65 & 3.76 & 3.34 \\
\hline 7 & $6 \mathrm{KM}$ & 3.27 & 3.37 & 3.38 & \\
\hline
\end{tabular}

Sedangkan hasil pengujian Short Circuit fasa fasa terbesar terjadi pada jarak $3 \mathrm{~km}$ dengan arus 5,52 A dan arus terkecil pada $6 \mathrm{~km}$ sebesar 3,35 A seperti pada Tabel 3. 
Tabel 3. Hasil pengujian arus hubung singkat fasa tanah

\begin{tabular}{|c|c|c|c|c|c|c|c|c|}
\hline \multirow{2}{*}{ No } & \multirow{2}{*}{ Jarak } & \multicolumn{2}{|c|}{ R-S } & \multicolumn{2}{|c|}{ ST } & \multicolumn{2}{|c|}{ RT } & \multirow{2}{*}{$\begin{array}{c}\text { Rata- } \\
\text { Rata (A) }\end{array}$} \\
\hline & & $\mathrm{R}(\mathrm{A})$ & S (A) & S (A) & $\mathrm{T}(\mathrm{A})$ & $\mathrm{R}(\mathrm{A})$ & $\mathrm{T}(\mathrm{A})$ & \\
\hline 1 & $3 \mathrm{KM}$ & 5.45 & 5.43 & 5.48 & 5.67 & 5.67 & 5.43 & 5.52 \\
\hline 2 & $3,5 \mathrm{KM}$ & 4.2 & 4.24 & 4.23 & 4.29 & 4.39 & 4.34 & 4.28 \\
\hline 3 & $4,5 \mathrm{KM}$ & 3.94 & 3.97 & 3.95 & 4.04 & 4.08 & 4.01 & 4.00 \\
\hline 4 & $6 \mathrm{KM}$ & 3.48 & 3.51 & 3.51 & 3.58 & 3.65 & 3.55 & 3.55 \\
\hline
\end{tabular}

\subsection{Simulasi Gangguan Fasa-Fasa}

Terdapat 2 simulasi yang dilakukan pada sistem ini yaitu simulasi gangguan short circuit fasa-fasa dan simulasi gangguan short circuit fasa-tanah. Gangguan short circuit fasa-fasa dilakukan pada 2 titik yaitu pada titik $3 \mathrm{Km}$ dan titik $6 \mathrm{Km}$ seperti pada skema pengujian pada Gambar 2. Dengan data hasil pengujian pada titik $3 \mathrm{Km}$ seperti yang terlihat pada Tabel 4 .

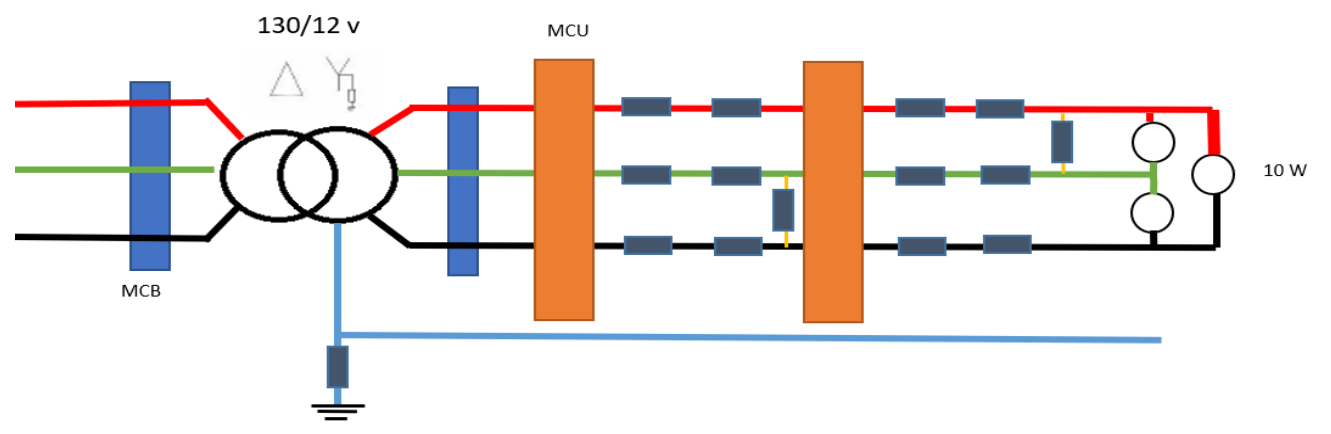

Gambar 2. Skema Pengujian Fasa-Fasa

Tabel 4. Hasil Pengujian Gangguan S Dan T

\begin{tabular}{|c|c|c|c|c|}
\hline No & Arus (A) & Jarak $(\mathrm{Km})$ & Error $(\%)$ & Jenis \\
\hline 1 & 5.8 & 3.13 & 4.33 & Gangguan S dan T \\
\hline 2 & 5.85 & 3.11 & 3.67 & Gangguan S dan T \\
\hline 3 & 5.83 & 3.12 & 4.00 & Gangguan S dan T \\
\hline 4 & 5.84 & 3.11 & 3.67 & Gangguan S dan T \\
\hline 5 & 5.86 & 3.1 & 3.33 & Gangguan S dan T \\
\hline Rata-rata & 5.84 & 3.11 & 3.67 & Gangguan S dan T \\
\hline
\end{tabular}

Dari data diatas terlihat sistem telah dapat mensimulasikan gangguan hubung singkat pada titik $3 \mathrm{~km}$ dengan arus rata-rata 5.84 Ampere dan jarak hasil perhitungan sejauh $3.11 \mathrm{~km}$ serta jenis gangguan yang terdeteksi adalah gangguan pada fasa $\mathrm{S}$ dan fasa T. Sedangkan pada titik $6 \mathrm{Km}$ hasil arus gangguan yang terdeteksi adalah 3.67 Ampere dan jarak hasil perhitungan sejauh $6.05 \mathrm{~km}$ serta jenis gangguan pada fasa $\mathrm{R}$ dan fasa S. seperti pada Tabel 5. 
Tabel 5. Hasil Pengujian Gangguan R Dan S

\begin{tabular}{|c|c|c|c|c|}
\hline No & Arus (A) & Jarak $(\mathrm{Km})$ & Error $(\%)$ & Jenis \\
\hline 1 & 3.64 & 6.11 & 1.83 & Gangguan R dan S \\
\hline 2 & 3.7 & 6.01 & 0.17 & Gangguan R dan S \\
\hline 3 & 3.68 & 6.04 & 0.67 & Gangguan R dan S \\
\hline 4 & 3.66 & 6.07 & 1.17 & Gangguan R dan S \\
\hline 5 & 3.67 & 6.06 & 1.00 & Gangguan R dan S \\
\hline Rata-rata & 3.67 & 6.05 & 0.83 & Gangguan R dan S \\
\hline
\end{tabular}

\subsection{Simulasi Gangguan Fasa-Fasa}

Dan untuk simulasi gangguan short circuit fasa-netral. Dilakukan pada titik $2 \mathrm{~km}$ dan $5 \mathrm{~km}$ Dengan skema pengujian seperti pada Gambar 3. Dengan data pada $2 \mathrm{~km}$ seperti pada Tabel 6.

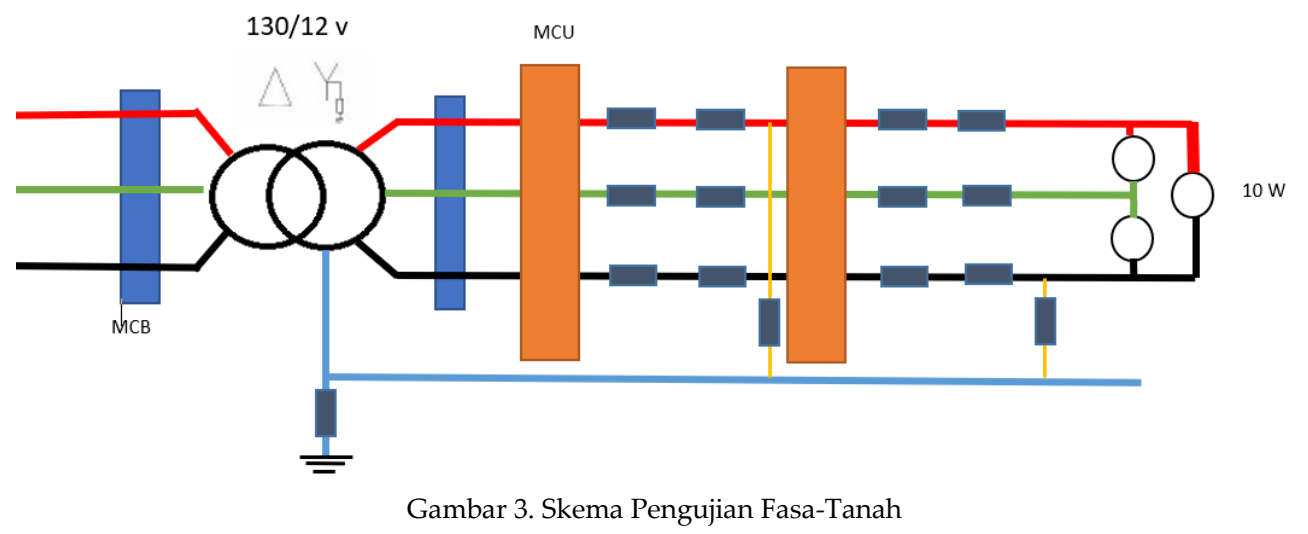

Tabel 6. Hasil Pengujian Gangguan R Dan N

\begin{tabular}{|c|c|c|c|c|}
\hline No & Arus $(\mathrm{A})$ & Jarak $(\mathrm{Km})$ & Error $(\%)$ & Jenis \\
\hline 1 & 6.02 & 2.32 & 16.00 & Gangguan R dan N \\
\hline 2 & 6 & 2.33 & 16.50 & Gangguan R dan N \\
\hline 3 & 6 & 2.33 & 16.50 & Gangguan R dan N \\
\hline 4 & 5.97 & 2.35 & 17.50 & Gangguan R dan N \\
\hline 5 & 5.98 & 2.34 & 17.00 & Gangguan R dan N \\
\hline Rata-rata & 5.99 & 2.33 & 16.50 & Gangguan R dan N \\
\hline
\end{tabular}

Dari data diatas terlihat sistem telah dapat mensimulasikan gangguan hubung singkat pada titik $2 \mathrm{~km}$ dengan arus rata-rata 5.99 Ampere dan jarak hasil perhitungan sejauh $2.33 \mathrm{~km}$ serta jenis gangguan yang terdeteksi adalah gangguan pada fasa $\mathrm{R}$ dan fasa N. Sedangkan pada titik $5 \mathrm{Km}$ hasil arus gangguan yang terdeteksi adalah 3.95 Ampere dan jarak hasil perhitungan sejauh $5.3 \mathrm{~km}$ serta jenis gangguan pada fasa $\mathrm{T}$ dan fasa N. seperti pada Tabel 7. 
Tabel 7. Hasil Pengujian Gangguan T Dan N

\begin{tabular}{|c|c|c|c|c|}
\hline No & Arus (A) & Jarak $(\mathrm{Km})$ & Error $(\%)$ & Jenis \\
\hline 1 & 3.93 & 5.33 & 6.60 & Gangguan T dan N \\
\hline 2 & 3.95 & 5.29 & 5.80 & Gangguan T dan N \\
\hline 3 & 3.97 & 5.26 & 5.20 & Gangguan T dan N \\
\hline 4 & 3.94 & 5.31 & 6.20 & Gangguan T dan N \\
\hline 5 & 3.94 & 5.31 & 6.20 & Gangguan T dan N \\
\hline Rata-rata & 3.95 & 5.3 & 6.00 & Gangguan T dan N \\
\hline
\end{tabular}

\section{Kesimpulan}

Dari perancangan dan pembuatan prototipe yang kemudian dilakukan pengujian parsial pada tiap komponen dan dilanjutkan pengujian integrasi pada sistem didapat kesimpulan sebagai berikut :

1. Penggunaan penyearah dan pembagi tegangan sebagai sensor tegangan cukup sesuai karena tegangan yang di sensor merupakan tegangan AC yang memiliki rating cukup kecil. Dan dari hasil pengujian sensor juga memiliki error yang relatif kecil.

2. Modul gangguan telah bila melakukan simulasi gangguan short circuit fasa-fasa dengan arus 5,67 A - 3,48A dan short circuit fasa-tanah dengan arus 6,17 A - 3.27A .

3. Sistem sudah bekerja cukup sesuai dengan perencanaan yaitu dapat trip dan mengetahui besar arus gangguan yang terjadi serta jenis gangguan short circuit yang terjadi dan juga telah dapat melakukan perhitungan titik lokasi gangguan.

4. Dari pengujian yang sudah dilakukan terlihat sistem sudah bisa memprediksi lokasi gangguan dengan selisih lokasi tebesar 360 meter atau 0,35 Km. Dan dengan error dalam persen terbesar $6,6 \%$.

\section{Daftar Pustaka}

[1] Sandy, Gora. 2019. “Gangguan pada Penyulang 20kV dan Penanganan pada Setiap Gangguan". Sidoarjo.

[2] PT. Perusahaan Listrik Negara (Persero). 1978. Standar Perusahaan Listrik Negara Nomor 2 Pasal 9 tentang pentanahan sistem distribusi listrik tiga fasa tiga kawat.

[3] Wahyudi, S. N, "Proteksi Sistem Distribusi Tenaga Listrik", Garamond, Depok, 2012.

[4] Amrie,Ulil "Rancang Bangun Over Current Relay Berbasis Arduino pada miniature jaringan 20kV" Jurnal Ilmiah, Teknik Elektro Industri, Politeknik Elektronika Negeri Surabaya.

[5] Burke, J.J. and Lawrence, D. J., "Characteristics of Fault Currents on Distribution Systems," IEEE Transactions on Power Apparatus and Systems, vol. PAS-103, no. 1, pp. 1-6, January 1984.

[6] Suswanto, D., "Sistem Distribusi Tenaga Listrik", Teknik Elektro Ubiversitas Negeri Padang,2009.

[7] J. Lewis Blackburn, "Protective Relaying Principles and Applications",Second Edition.

[8] Sadawe, Krisna dan Kutsuro, Iqbal Asad "Desain dan Prototipe Sistem Deteksi Gangguan Impedansi Tinggi pada SUTM 20 kV dengan Sistem Pelaporan Gangguan Menggunakan Komunikasi Data Modul GSM" Tugas Akhir, Departemen Teknik Elektro Otomasi ITS,Surabaya, 2017. 
[9] Murtadho, Moch. Yogi, "Prototipe Sistem Pelaporan Gangguan Beserta Posisi Gangguan Pada Jaringan Distribusi", Tugas Akhir, Program D3 Teknik Elektro FTIITS, Surabaya, 2016.

[10] PT. Perusahaan Listrik Negara (Persero). 1995. Standar Perusahaan Listrik Negara Nomor 64 tentang impedansi kawat penghantar.

[11]Heru Dibyo Laksono, M. Nasir Sonni "Perancangan dan Implementasi Relay Arus Lebih Sesaat Berbasis Microcontroller". Jurusan Teknik Elektro, Univeristas Andalas Padang Sumatera Barat. 2007. 
